\title{
Linguistic diversity of natural UNESCO world heritage sites: bridging the gap between nature and culture
}

\author{
Suzanne Romaine ${ }^{1}$ - L. J. Gorenflo ${ }^{2}$
}

Received: 21 October 2016/Revised: 17 March 2017/Accepted: 30 March 2017/

Published online: 17 April 2017

(C) The Author(s) 2017. This article is an open access publication

\begin{abstract}
UNESCO Natural World Heritage Sites (WHSs) are some of the most important biophysical and geological places on Earth, yet nearly half are endangered or face considerable risks from ever-expanding human impacts. Often sites have people living within or nearby who speak different languages, many of which are unique and similarly endangered. Here we examine the co-occurrence of Natural WHSs with languages, as a key index of cultural diversity, to identify locations for integrative conservation opportunities aimed at protecting human and non-human diversity. Our analysis reveals many WHSs with high linguistic diversity, as well as endangered sites with associated indigenous languages and endangered languages that intersect Natural WHSs. Results identify Australia as the continent which has the greatest number of Natural WHSs, many cooccurring with highly endangered languages. Engaging speakers of indigenous languages often can help maintain nature, while efforts to conserve Natural WHSs can help preserve settings that enabled indigenous languages and cultures to emerge and persist.
\end{abstract}

Keywords Linguistic and cultural diversity - UNESCO natural world heritage sites · Conservation $\cdot$ Endangerment

Communicated by Peter Bridgewater.

Electronic supplementary material The online version of this article (doi:10.1007/s10531-017-1340-x) contains supplementary material, which is available to authorized users.

Suzanne Romaine

suzanne.romaine@gmail.com

L. J. Gorenflo

ljg11@psu.edu

1 Merton College, University of Oxford, Oxford OX1 4JD, UK

2 Department of Landscape Architecture, The Pennsylvania State University, University Park, PA 16802-1912, USA 


\section{Introduction}

As Earth's population approaches 7.4 billion, important parts of our planet's natural and cultural heritage increasingly are under duress from efforts to meet unprecedented human demands for food and other resources (Foley et al. 2005). In response, conservationists and governments have developed protected areas-places designated and managed for longterm conservation of cultural values, nature, and associated ecosystem services-to help maintain noteworthy localities (Dudley 2008). Protected areas vary both in function and importance, with those recognized as particularly significant internationally designated as World Heritage Sites (WHSs) by the United Nations Educational, Scientific and Cultural Organization (UNESCO). As one of the most widely ratified international conservation instruments, the World Heritage Convention (WHC) has set standards for maintaining 1052 protected areas in 165 countries (UNESCO n.d.). Despite broad recognition of their role in representing irreplaceable pieces of our planet's cultural and natural heritage, WHSs are also threatened; currently 55 are officially listed as endangered and many others are experiencing pressure from an ever-expanding human footprint. Consistent with varying performance of protected areas in general (Leverington et al. 2010), the future of world heritage rests on developing strategies to ensure WHS survival.

Despite their emphasis on biophysical and geological features, Natural WHSs often occur in diverse human contexts. Analysis of global population (Bright et al. 2011) indicates considerable human presence: in 2010, more than 40.4 million people lived inside these sites or within $10 \mathrm{~km}$ of their borders. Although people often pose challenges to conserving nature, the need for integrative conservation approaches reconciling the wellbeing of nature, people, and culture is increasingly viewed as essential for sustaining global diversity. Natural WHSs provide unique opportunities for understanding the depth and impact of links between humans and places in different cultural contexts. Languages play a key role in linking people, culture and the environment. With virtually every major aspect of human culture depending on language for its transmission, linguistic diversity is often used as a benchmark or proxy for cultural diversity. Research over the past two decades reveals high linguistic diversity in locations recognized primarily for their natural characteristics (Nettle and Romaine 2000; Maffi 2005), with many protected areas in highly biodiverse regions co-occurring with large numbers of languages (Gorenflo et al. 2012 , 2014). Such overlap suggests a relationship between biological and cultural-linguistic diversity, referred to as "biocultural diversity" (Pretty et al. 2009; Loh and Harmon 2014). Conserving biocultural diversity requires maintaining numerous small communities whose lifestyles depend on healthy ecosystems. Without such resources, these groups find it hard to maintain the lifeways and cultural identities on which transmission and vitality of their languages depend. As repositories of traditional ecological knowledge, indigenous languages represent important assets in natural and cultural resource management and sustainable development, as recognized in the Convention on Biological Diversity (1992), the Convention for the Safeguarding of Intangible Cultural Heritage (UNESCO 2003), the United Nations Declaration on the Rights of Indigenous Peoples (United Nations 2007) and other international instruments.

Natural WHSs provide an opportunity to examine the co-occurrence of biological and linguistic diversity in prominent locations. Despite the potential for developing conservation strategies that help maintain local cultures as well as Natural WHSs, the number of indigenous languages associated with WHSs currently is unknown (Palmer 2016). Here, we document the languages that co-occur with the 238 current Natural WHSs (including 35 
mixed Natural-Cultural WHSs), as well as languages found in close proximity (within 10 and $25 \mathrm{~km}$ ) of those sites. We also refine this analysis through examining linguistic diversity associated with endangered Natural WHSs, and WHSs associated with endangered languages. Results indicate a number of Natural WHSs in areas with considerable linguistic diversity, marking potential opportunities to engage multiple indigenous groups to help conserve these important localities. Our analyses also reveal instances where endangered Natural WHSs co-occur with areas where indigenous languages are spoken, and instances where endangered languages co-occur with Natural WHSs, in both cases marking priority conservation targets. We discuss implications of these results for developing protected area management strategies and programs for indigenous language maintenance that can help protect some of Earth's most important places and their culturallinguistic diversity.

\section{Materials and methods}

This study uses precise locational data for UNESCO Natural WHSs and indigenous languages. Both datasets are available in a geographic information system (GIS) format, enabling systematic analysis of their co-occurrence to identify any spatial relationship between WHSs and indigenous languages.

UNESCO Natural WHSs are localities containing internationally significant natural heritage - natural features (physical or biological formations); geological or physiological formations, including habitat supporting threatened plant and animal species; and natural sites of outstanding value to science, conservation, or natural beauty (UNESCO 2005, 2012a). Articles 1 and 2 of the WHC define criteria for nominating localities as "natural" and "cultural heritage". Properties designated as "mixed cultural and natural heritage" must satisfy a part or the whole of the definitions of both cultural and natural heritage laid out in Articles 1 and 2 of the WHC (UNESCO 2016: 10-11).

Article 1 considers the following as "cultural heritage" (UNESCO 2016:10):

- Monuments: architectural works, works of monumental sculpture and painting, elements or structures of an archaeological nature, inscriptions, cave dwellings and combinations of features, which are of Outstanding Universal Value from the point of view of history, art or science;

- Groups of buildings: groups of separate or connected buildings which, because of their architecture, their homogeneity or their place in the landscape, are of Outstanding Universal Value from the point of view of history, art or science;

- Sites: works of man or the combined works of nature and of man, and areas including archaeological sites which are of Outstanding Universal Value from the historical, aesthetic, ethnological or anthropological points of view.

Article 2 considers the following as "natural heritage" (UNESCO 2016:11):

- Natural features consisting of physical and biological formations or groups of such formations, which are of Outstanding Universal Value from the aesthetic or scientific point of view;

- Geological and physiographical formations and precisely delineated areas which constitute the habitat of threatened species of animals and plants of Outstanding Universal Value from the point of view of science or conservation; 
- Natural sites or precisely delineated natural areas of Outstanding Universal Value from the point of view of science, conservation or natural beauty.

Precise locational information on these sites, along with additional data, are maintained in GIS format by the World Database on Protected Areas (WDPA) (IUCN and United Nations Development Programme-World Conservation Monitoring Centre 2016). Distributed in 96 countries across the globe (Fig. 1a), the 238 current Natural WHSs (including 35 mixed Natural-Cultural WHSs) occur in a range of geographic settings and represent a wide variety of natural heritage.

The best and most comprehensive source of global data on languages is maintained by SIL International (SIL n.d.), a non-profit organization that publishes a catalog of the world's languages called Ethnologue. In collaboration with the editors of Ethnologue,

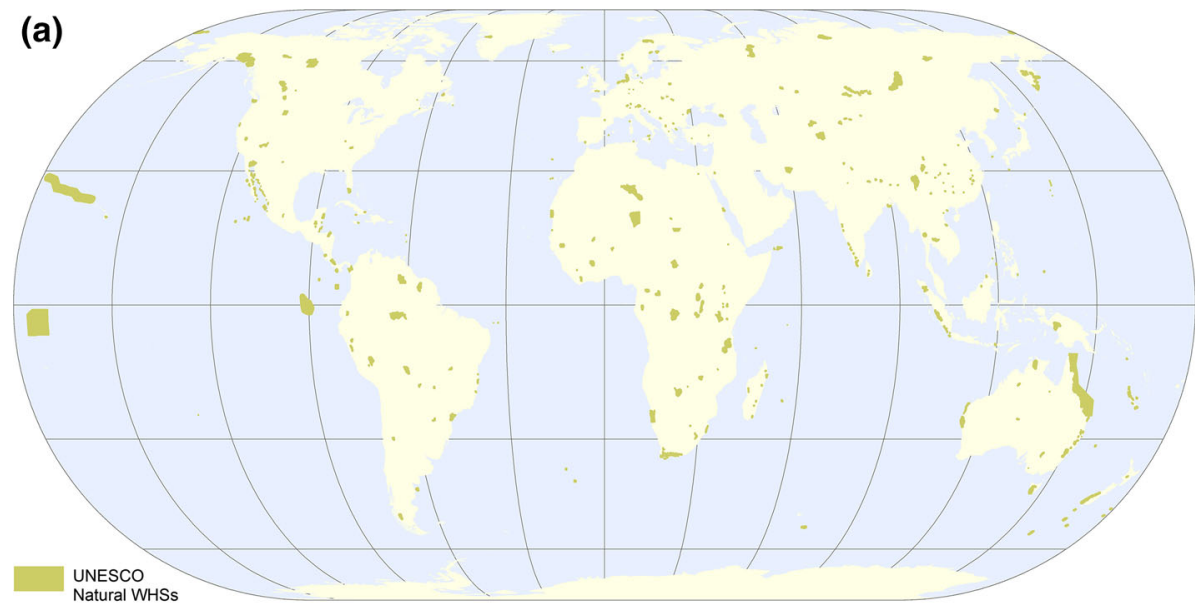

Data source: IUCN and UNEP-WCMC 2016

Projection: Eckert IV

Note: Site sizes exaggerated slightly for better visibility

(b)

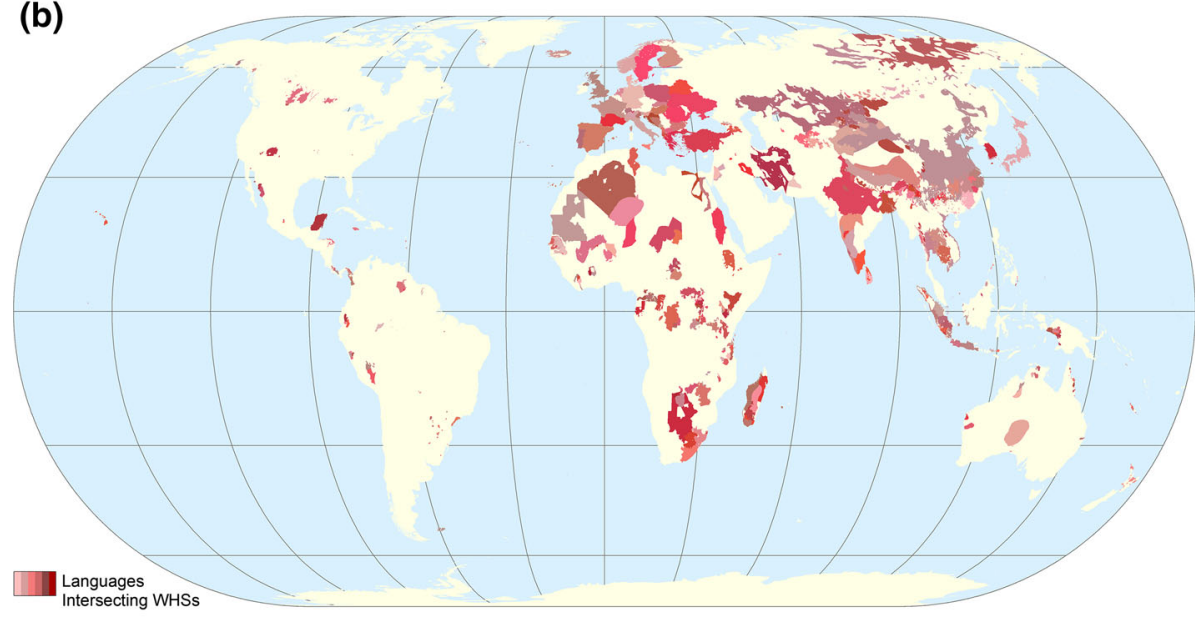

Data source: Global Mapping International 2015 Projection: Eckert IV

Fig. 1 UNESCO natural WHSs (a), and indigenous languages that co-occur with Natural WHSs (b) 
Global Mapping International (GMI) began to map individual languages using GIS technology, recently releasing GIS datasets based on the 17th edition of Ethnologue containing information on 7106 languages (Global Mapping International 2015a, b; Lewis et al. 2013). One dataset contains polygons defining the spatial extent of 6425 languages, along with selected information from Ethnologue (e.g., language family, estimated number of speakers, level of endangerment). Here we focus on indigenous and non-migrant languages (hereafter "indigenous languages"), those associated with a particular area and people rather than languages whose extent has spread with colonial expansion (e.g., English in the United States, Canada, Australia, and New Zealand).

We analyze co-occurrence by determining which languages share at least part of their geographic extent with Natural WHSs, or occur at specified proximities to WHSs. Our initial analysis focuses on all indigenous languages and all Natural WHSs. In addition, we examine the 18 Natural World Heritage Sites categorized as endangered-either in specific imminent danger or facing major threats (UNESCO 2016). We also examine languages in danger of disappearing, based on the following criteria:

- 1000 or fewer speakers;

- 10,000 or fewer speakers; and

- Expanded Graded Intergenerational Disruption Scale (EGIDS), a measure of language vitality, corresponding to assessments as "threatened", "shifting", "moribund", "nearly extinct", or "dormant" (Lewis and Simons 2010).

\section{Results}

GIS analysis reveals that 445 indigenous languages shared at least part of their geographic range with a Natural WHS, about $6.3 \%$ of the world's linguistic diversity occurring on roughly $1.0 \%$ of the planet's terrestrial area (excluding Antarctica). Another 91 languages lie within $10 \mathrm{~km}$ of the WHSs, bringing the total to 536. Some 160 more occur within $25 \mathrm{~km}$ of a Natural WHS, increasing the total to 696 , or $9.8 \%$ of all languages. The cooccurrence of indigenous languages within or in proximity to Natural WHSs reveals a striking presence of linguistic-cultural diversity near protected areas defined largely for their global importance to nature. Nevertheless, the geographic distribution of languages co-occurring with Natural WHSs is uneven, with larger numbers in Africa and Asia-each with more than 140 languages intersecting a WHS - and many fewer in Oceania and South America (Table 1). These geographic discrepancies largely reflect differences in the distribution of Natural WHSs, though the number of languages intersecting these sites is greater in Africa and Asia than one would expect based on site distribution.

Although most Natural WHSs $(78.1 \%)$ co-occur with at least one indigenous language, there are marked differences in language numbers (Fig. 1b). Geographically, dramatic discrepancies appear when comparing the New World, Australia, and New Zealand to the remainder of the planet, with languages intersecting WHSs in North and South America and those large Pacific island nations often scattered and featuring small geographic ranges compared to other regions, notably Europe and Asia. In large part, this contrast reflects differences in historical patterns of contact, conquest, and settlement, the first areas largely dominated by European colonial languages (mainly English, Portuguese, and Spanish) while many other regions maintained a broader geographic presence of indigenous languages. Australia shows this pattern in microcosm, with many indigenous languages having been replaced by English. Africa also contains many languages with broad 
Table 1 Summary of Natural WHS distribution, and co-occurrence of WHSs and indigenous languages in selected categories, by major geographic region

\begin{tabular}{llllll}
\hline Region & $\begin{array}{l}\text { Natural } \\
\text { WHSs }^{\mathrm{a}}\end{array}$ & $\begin{array}{l}\text { All languages } \\
\text { intersecting } \\
\text { WHSs }\end{array}$ & EGIDS & $\begin{array}{l}\text { Languages } \\
\text { with } \leq 10,000 \\
\text { speakers }\end{array}$ & $\begin{array}{l}\text { Languages } \\
\text { with } \leq 1000 \\
\text { speakers }\end{array}$ \\
\hline Africa & 53 & 147 & 18 & 20 & 7 \\
Antarctica & 1 & - & - & - & - \\
Asia & 62 & 149 & 36 & 23 & 6 \\
Australia & 15 & 20 & 19 & 20 & 18 \\
Europe & 35 & 43 & 5 & 2 & - \\
North America & 39 & 33 & 12 & 14 & 7 \\
Oceania & 11 & 33 & 16 & 24 & 3 \\
South America & 22 & 23 & 12 & 10 & 50 \\
Total & c & 445 & 117 & 112 & 5 \\
\hline
\end{tabular}

a WHSs world heritage sites

b EGIDS expanded graded intergenerational disruption scale (categories used comprise 6b, threatened; 7 , shifting; 8a, moribund; 8b, nearly extinct; and 9, dormant)

c Totals for some language columns may not equal sums of those columns due to languages occurring in more than one continent

geographic ranges that co-occur with Natural WHSs, though their ranges are not as large as those in Europe and Asia. Languages with particularly large geographic presence, such as Xhosa, spoken by more than 8 million people in southern Africa, tend to be in good condition and feature large numbers of speakers; the opposite tends to be the case for languages with limited geographic ranges, such as Hadza, a language isolate (i.e., unrelated to any existing language) spoken by a dwindling population of around 800 hunter-gatherers within and near Ngorongoro Conservation Area in Tanzania.

With large numbers of people living in or near Natural WHSs, conserving these sites is a major challenge as all experience some level of direct or indirect human impact. World Wide Fund for Nature has declared 114 Natural WHSs and mixed Cultural-Natural WHSs at risk from harmful mining and other industrial activities (Dalberg Global Development Advisors 2016). UNESCO officially categorizes 18 of the 238 sites as endangered. Endangered sites are those where key species are declining, where natural beauty or scientific value is declining, or where human encroachment is occurring. Potentially endangered sites are those whose legal status has changed, where planned development or resettlement threatens the site, where armed conflict occurs, where site management is inadequate, or where the threat of climatic, geologic, or environmental impacts exists. Thirteen endangered Natural WHSs occur in Africa, with the remaining five scattered among four major regions (Table 2; Fig. 2a). The number of indigenous languages that cooccur with these endangered sites reflects the distribution of the sites themselves: 71 of the 90 total languages lie in Africa, with concentrations occurring in central Africa and Madagascar (Fig. 2b). Although only one endangered site lies in Asia-Tropical Rainforest Heritage of Sumatra-it co-occurs with 16 languages, marking a locality with considerable linguistic-cultural diversity (see Figure S7). Most of these languages are both large and not endangered (e.g., Malay, Aceh, and Javanese), though at least three (Gayo, Kerinci, and Lampung Api) are threatened. Remaining languages that co-occur with endangered WHSs are scattered across three broad regions. 
Table 2 Summary of endangered Natural WHS distribution, and co-occurrence of those WHSs and indigenous languages in selected categories, by major geographic region

\begin{tabular}{llllll}
\hline Region & $\begin{array}{l}\text { Natural } \\
\text { WHSs }\end{array}$ & $\begin{array}{l}\text { All languages } \\
\text { intersecting } \\
\text { WHSs }\end{array}$ & EGIDS & $\begin{array}{l}\text { Languages } \\
\text { with } \leq 10,000 \\
\text { speakers }\end{array}$ & $\begin{array}{l}\text { Languages } \\
\text { with } \leq 1000 \\
\text { speakers }\end{array}$ \\
\hline Africa & 13 & 71 & 9 & 11 & 2 \\
Antarctica & - & - & - & - & - \\
Asia & 1 & 16 & 3 & - & - \\
Australia & - & - & - & - & - \\
Europe & - & - & - & - & - \\
North America & 2 & 1 & - & - & - \\
Oceania & 1 & 1 & - & 1 & - \\
South America & 1 & 1 & - & 1 & - \\
Total & 18 & 90 & 12 & 13 & 2 \\
\hline
\end{tabular}

WHSs world heritage sites, EGIDS expanded graded intergenerational disruption scale (categories used comprise $6 \mathrm{~b}$, threatened; 7 , shifting; $8 \mathrm{a}$, moribund; $8 \mathrm{~b}$, nearly extinct; and 9 , dormant)

We use three different criteria for assessing language endangerment. EGIDS is a measure consisting of 13 levels with each higher value representing lessened intergenerational transmission (Lewis and Simons 2010). Figure 3a shows the 117 indigenous languages that meet the EGIDS criteria as endangered and co-occur with Natural WHSs (see also Table 1, Table S1). The largest number of these languages occurs in Asia. However, a large percentage of the languages are endangered in Oceania and, especially, Australia, where 19 of the 20 languages intersecting a Natural WHS meet EGIDS criteria for endangered. We also considered number of speakers as an indicator of endangerment, based on the assumption that languages with smaller numbers of speakers are more susceptible to disruption from external pressures that can lead to a range of culture change, including language loss (Nettle and Romaine 2000). We consider two thresholds: 10,000 or fewer speakers, and 1000 or fewer speakers. Some 112 languages with 10,000 or fewer speakers co-occur with Natural WHSs, distributed among seven regions, fairly evenly among five of them (Fig. 3b; see also Table 1 and Table S1). A total of 50 languages with 1000 or fewer speakers intersect WHSs (Fig. 3c), distributed among six regions, with Australia accounting for the largest number by far. The three criteria for linguistic endangerment yield three very different maps, the main contrasts being the major region emphasized and the spatial extent of the languages (those with smaller numbers of speakers tending to cover less geographic space). Table 2 presents results of analyzing the cooccurrence of endangered languages with endangered Natural WHSs, the total numbers being substantially smaller for all Natural WHSs (and difficult to show on a global map due to broad dispersion of languages with limited geographic extents).

The number of indigenous languages that co-occur with Natural WHSs varies widely, ranging from zero in 52 sites to as many as 24 in the Western Ghats WHS of India. The Western Ghats, with its high level of endemic species, is one of the eight hottest of biodiversity hotspots, hosting at least 325 threatened bird, reptile, amphibian and fish species. Two ecoregions in the Western Ghats have been included in the World Wildlife Fund's Global 200 Priority Ecoregions for Conservation, and the area is also an important Global Endemic Bird Area, again in recognition of its remarkable biological diversity. The Western Ghats WHS comprises 39 localities spread across the states of Kerala, Tamil 


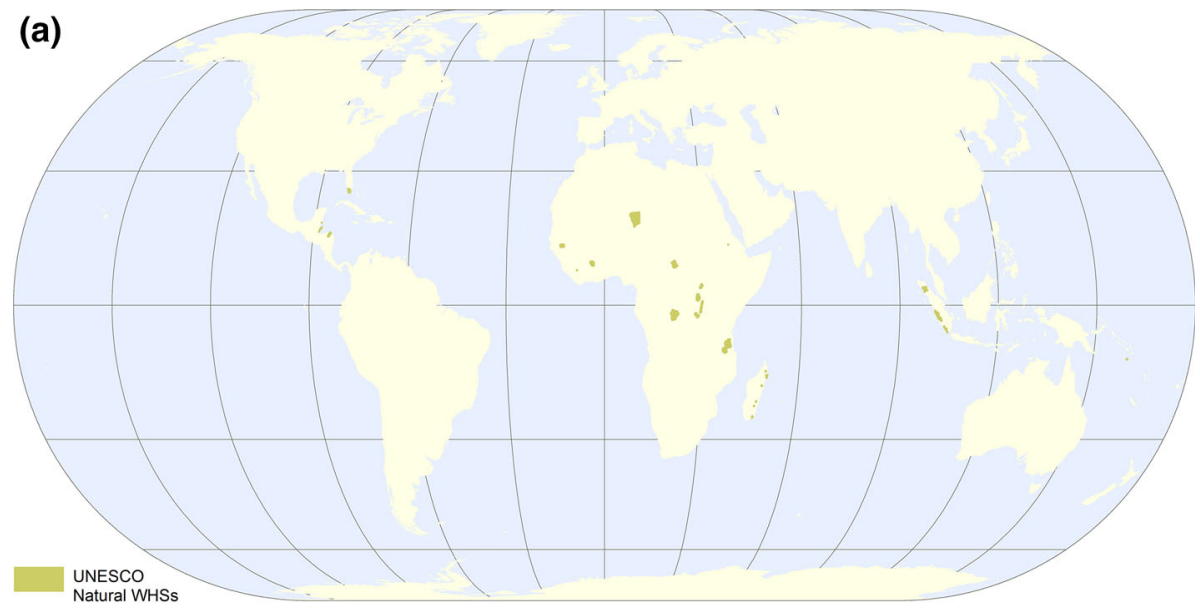

Data source: IUCN and UNEP-WCMC 2016 Projection: Eckert IV

Note: Site sizes exaggerated slightly for better visibility

(b)

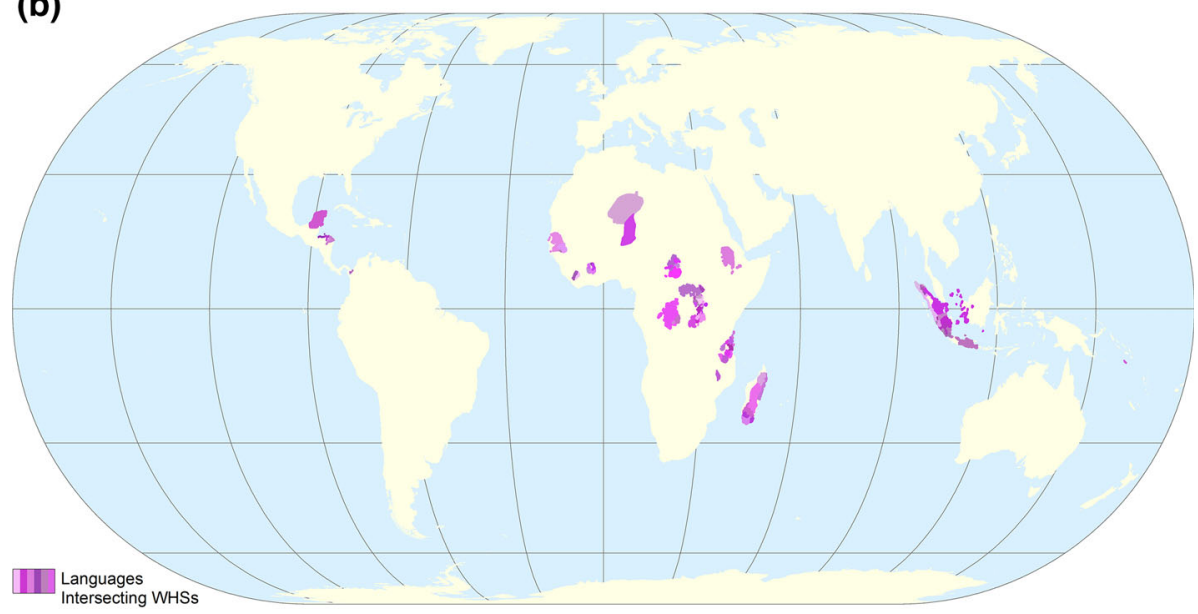

Data source: IUCN and UNEP-WCMC 2016 Projection: Eckert IV

Note: Language areas exaggerated slightly for better visibility

Fig. 2 Endangered Natural WHSs (a); indigenous languages that co-occur with endangered Natural WHSs (b)

Nadu, Karnataka and Maharastra in southwestern India (Fig. 4). Roughly 40 indigenous tribal communities reside in the vicinity of the WHS, with more than 100,000 people whose livelihoods depend on gathering forest resources within the site, and another 100,000 or more living in areas bordering the site (Bijoy 2014). Although several of the 24 indigenous languages co-occurring with this WHS complex are large regional languages such as Kannada, Malayalam, and Tamil, nearly half are far smaller and endangered, determined by EGIDS (Allar, Kurichiya, Mannan, Thachanadan) or speakers numbering fewer than 10,000 (Allar, Atapaddy Kurumba, Kudiya, Mala Malasar, Malapandaram, Mannan, Muduga, Paliyan, Thachanadan). 
Australia represents a particularly interesting case because the so-called Australian language family is the most endangered in the world, with $94 \%$ of languages threatened with extinction or already extinct since 1970, the fastest decline in linguistic diversity of any country (Loh and Harmon 2014). Australia has lost many indigenous languages since British colonization in the late 18th century. Assimilationist policies practiced by missions, government, and schools disrupted intergenerational transmission of language and culture to such an extent that currently only 120 languages remain of more than 250 once spoken by around 600 groups that lived in Australia at least 50,000 years before European contact (Marmion et al. 2014). The 2011 Census lists 60,550 speakers of indigenous languages, representing $11.6 \%$ of the population identifying as Aboriginal and concentrated primarily in more remote parts of 4 areas-the Northern Territory, Queensland, Western Australia and South Australia (Biddle 2012). Only around 15 languages are still strong and spoken by all age groups, five fewer than 10 years ago (Australian Institute of Aboriginal and Torres Strait Islander Studies and Federation of Aboriginal and Torres Strait Islander Languages 2005). Based on EGIDS criteria, 115 indigenous languages in Australia are endangered; all are spoken by 10,000 or fewer individuals, and all but 13 languages are spoken by 1000 or fewer.

A total of 15 UNESCO Natural WHSs lie in Australia, co-occurring with 20 indigenous languages (Fig. 5a; Table 3). All but one (Pitjantjatjara, in Uluru-Kata Tjuta National Park) are endangered based on EGIDS criteria, and all but two (Pitjantjatjara, and Gunwinggu in Kakadu National Park) have 1000 or fewer speakers. As with global patterns, co-occurrence of languages with Natural WHSs varies widely, reflecting historical patterns of contact and settlement. Some reserves, such as Fraser Island, the Greater Blue Mountains Area, and the Willandra Lakes Region, currently share their territory with no indigenous languages, largely due to massacres, forced removal, and resettlement. Other WHSs intersect several languages. Great Barrier Reef National Park intersects eight indigenous languages lying along the northeastern coast (Dyaabugay, Kuku-Yalanji, Guguyimijir, Kuuku-Ya'u, Lamu Lamu, Umpila, Warrgamay, and Yidiny); it abuts the Wet Tropics of Queensland WHS, which intersects five languages (four also co-occurring with the Great Barrier Reef). By EGIDS criteria, all are endangered, and all are spoken by 1000 or fewer individuals. Kakadu National Park co-occurs with five indigenous languages, two of which (Amurdak and Gagadu) have only one known remaining speaker (Fig. 5b). Four languages (Wageman in Kakadu, Bayungu in Ningaloo Coast, Yinggarda in Shark Bay and Warrgamay in the Wet Tropics of North Queensland) have 10 or fewer speakers.

The possible nomination of Cape York in northern Queensland for World Heritage listing as a mixed site or cultural landscape could add as many as 37 language groups (Logan 2014). As a hotspot of indigenous biocultural knowledge, it offers excellent opportunities for engaging local communities in stewardship (Ens et al. 2015), but its size and complexity from both a geographic and cultural-linguistic perspective may strain the capacity of traditional owners, who are already dealing with two WHSs - the Wet Tropics of Queensland and the Great Barrier Reef (Hill et al. 2011). The Yalanji language group, traditionally never separated, is already split into Western and Eastern contingents (Figgis et al. 2012). Likewise, Girringun's traditional sea country falls within these same two WHSs, the Wet Tropics and the Great Barrier Reef, the latter narrowly escaping endangered listing in 2015.

Other instances of Natural WHS co-occurrence with languages are also noteworthy. Electronic Supplementary Material contains maps for Natural WHSs with 10 or more languages (Figures S2 through S9), including three sites officially listed as endangered. 

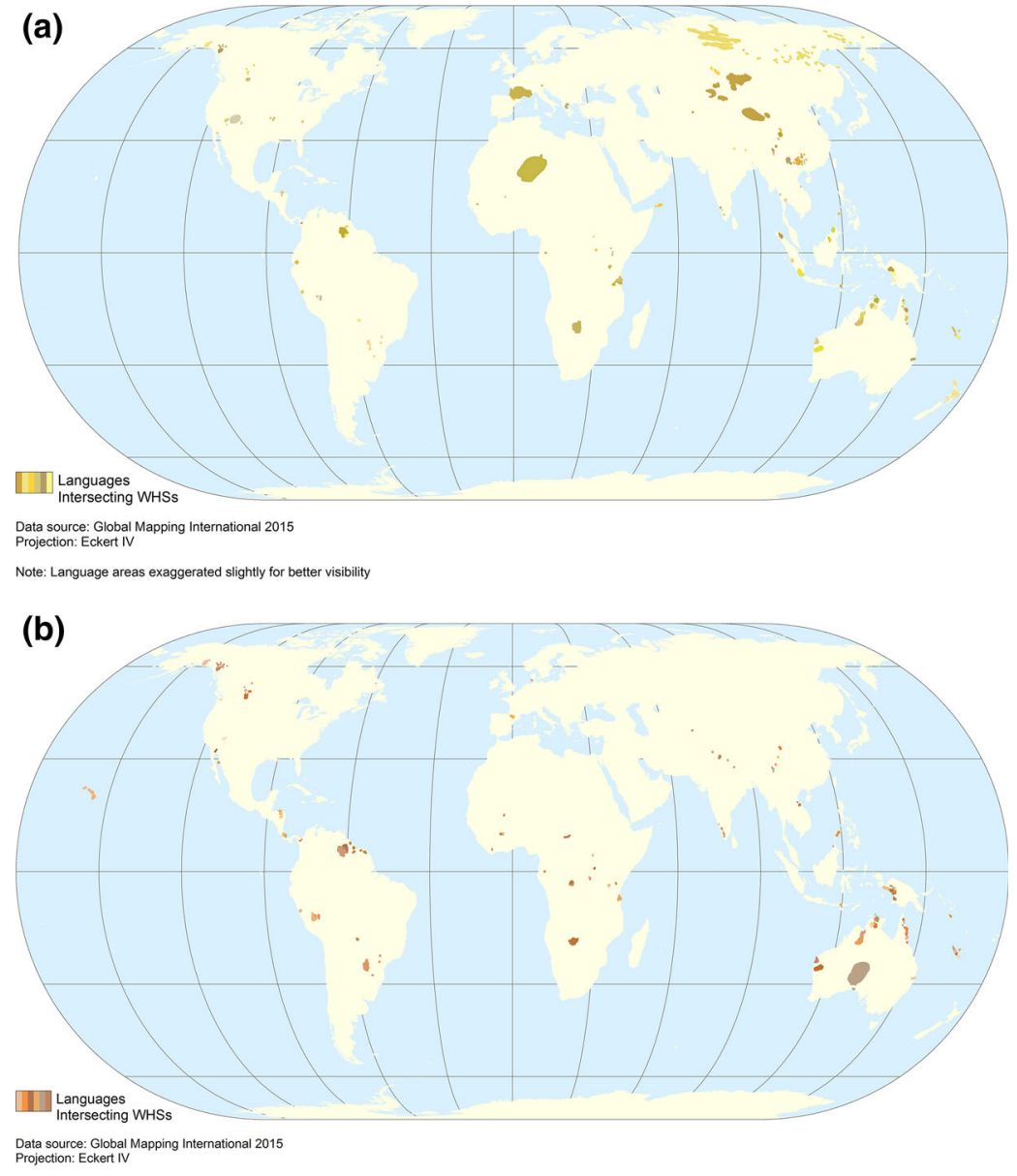

Note: Language areas exaggerated slighly for better visibility

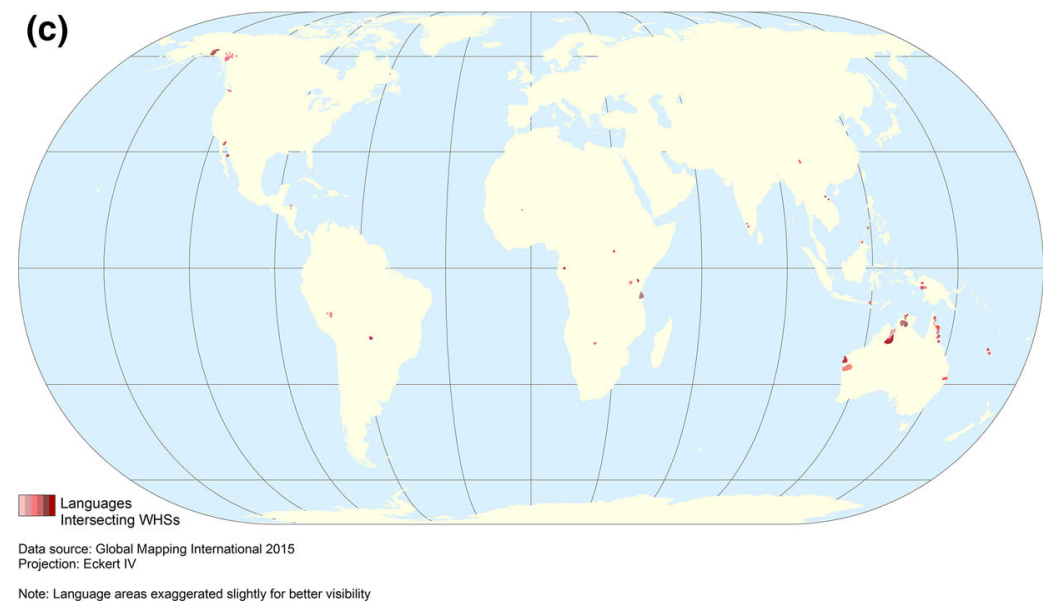


4 Fig. 3 Indigenous languages with specific levels of EGIDS endangerment that co-occur with Natural WHSs (a); indigenous languages with 10,000 or fewer speakers that co-occur with Natural WHSs (b); and indigenous languages with 1000 or fewer speakers that co-occur with Natural WHSs (c)

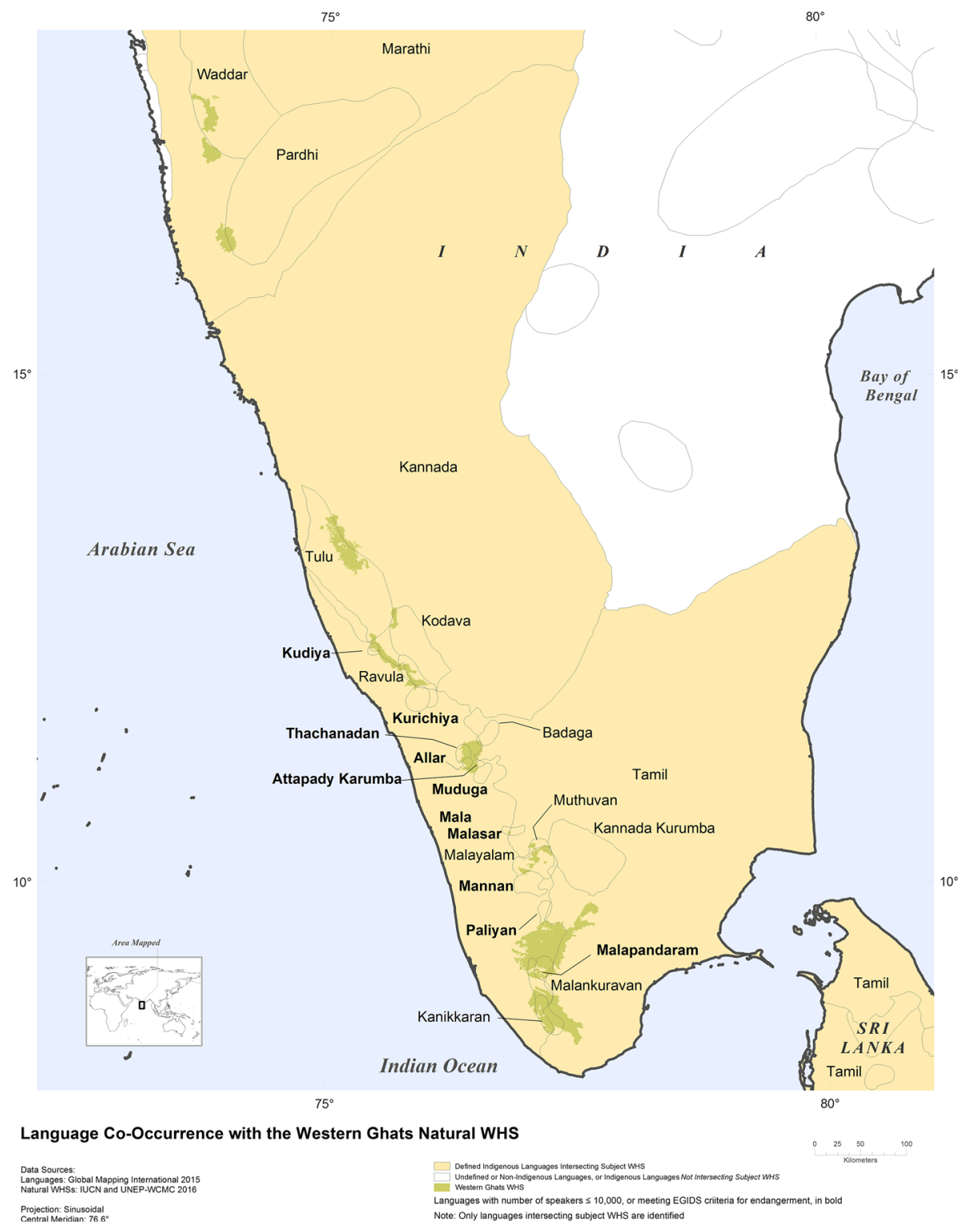

Fig. 4 Indigenous languages that co-occur with the Western Ghats WHS 
(a)

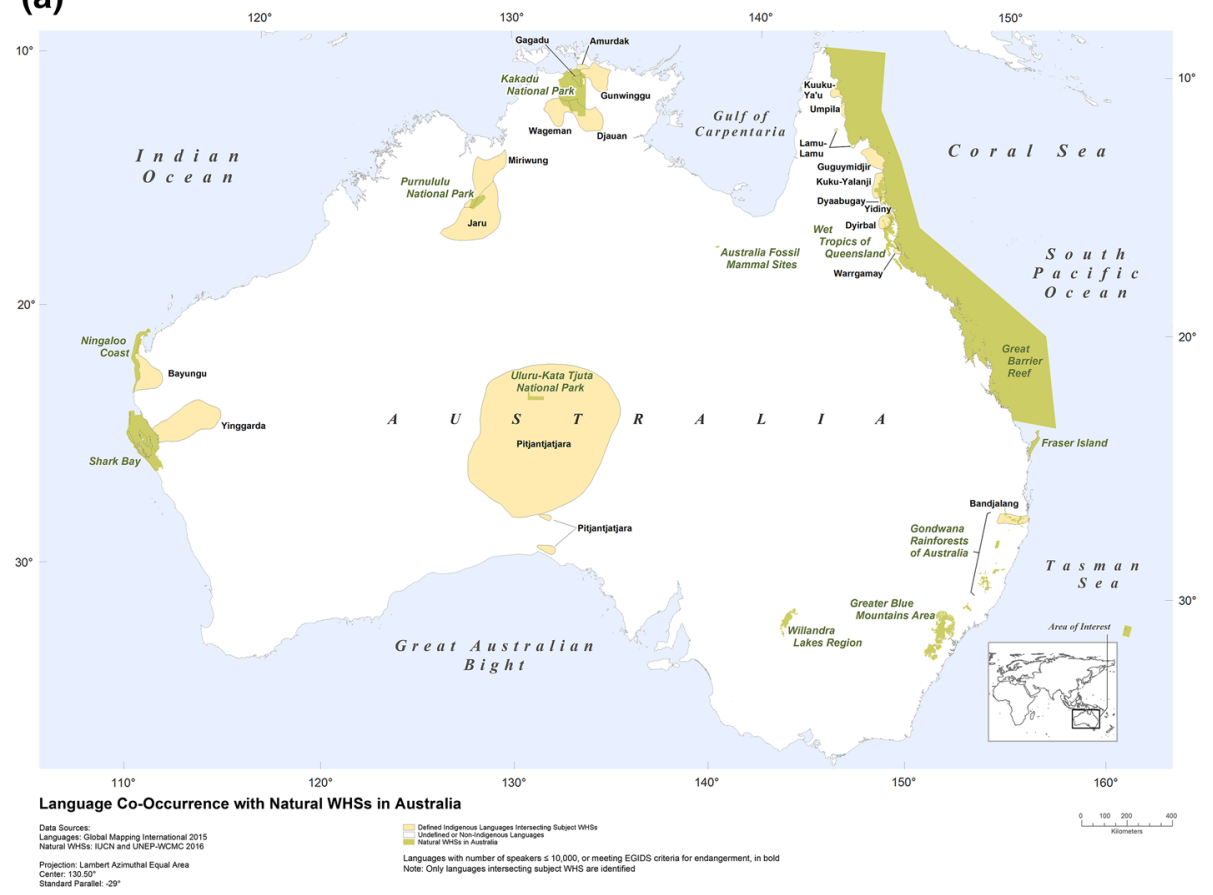

(b)

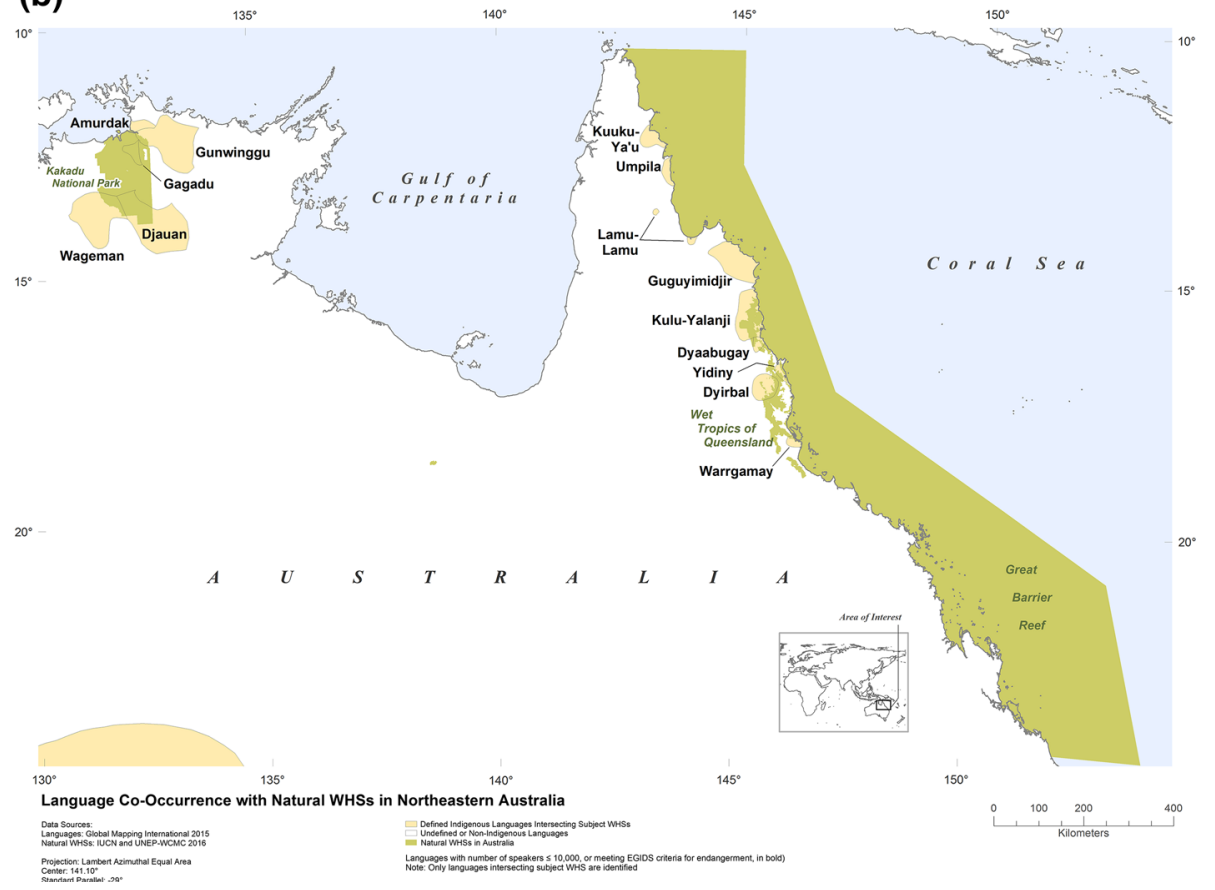

Fig. 5 Indigenous languages that co-occur with Natural WHSs in Australia (a), and in northeastern Australia (b) 
Table 3 Natural WHSs in Australia and Statistics on Indigenous Languages that Intersect Them

\begin{tabular}{lllll}
\hline Natural WHS site & $\begin{array}{l}\text { Total } \\
\text { languages }\end{array}$ & $\begin{array}{l}\text { EGIDS } \\
\text { languages }^{\mathrm{a}, \mathrm{b}}\end{array}$ & $\begin{array}{l}\text { Languages } \\
\leq 10 \mathrm{~K} \\
\text { speakers }^{\mathrm{b}}\end{array}$ & $\begin{array}{l}\text { Languages } \\
\leq 1 \mathrm{~K} \\
\text { speakers }^{\mathrm{b}}\end{array}$ \\
\hline $\begin{array}{l}\text { Australian Fossil Mammal } \\
\text { Sites (Riversleigh, Naracoorte) }\end{array}$ & - & - & - & - \\
Fraser Island & - & - & - & - \\
Gondwana Rainforests of Australia & 1 & 1 & 1 & 1 \\
Great Barrier Reef & 8 & 8 & 8 & 8 \\
Greater Blue Mountains Area & - & - & - & - \\
Kakadu National Park & 5 & 5 & 5 & 4 \\
Lord Howe Island Group & - & - & - & - \\
Macquarie Island & - & - & - & - \\
Ningaloo Coast & 1 & 1 & 1 & 1 \\
Purnululu National Park & 2 & 2 & 2 & 2 \\
Shark Bay, Western Australia & 1 & 1 & 1 & - \\
Tasmanian Wilderness & - & - & - & - \\
Uluru-Kata Tjuta National Park & 1 & - & 1 & 5 \\
Wet Tropics of Queensland & 5 & 5 & 5 & - \\
Willandra Lakes Region & - & - & - & 1 \\
\hline
\end{tabular}

\footnotetext{
${ }^{a}$ EGIDS values for endangerment consist of $6 \mathrm{~b}$ ("threatened"), 7 ("shifting"), 8a ("moribund"), and $8 \mathrm{~b}$ ("nearly extinct")

${ }^{\mathrm{b}}$ For language endangerment, assessment based on EGIDS assessment and number of speakers for the language polygons intersecting the Natural WHS in question; “-"equals 0
}

\section{Discussion and conclusions}

As the first international instrument addressing protection of both natural and cultural heritage, the WHC is a powerful tool for establishing models for conservation. Because the human context of each Natural WHS varies considerably, no universal model will work, requiring strategies tailored to particular situations. Although defining specific management programs for conserving biodiversity and linguistic diversity is beyond the scope of this study, our analysis has identified some key locations for further exploration. As the nation with the greatest number of Natural WHSs, as well as the greatest declines in both biological and linguistic diversity of any continent (McDonald et al. 2015; Loh and Harmon 2014), Australia would provide an opportunity for future examination of strategies to integrate conservation of natural and cultural-linguistic diversity.

Our analysis also identified many other UNESCO Natural WHSs that are rich in cultural-linguistic diversity, but face challenges due to the erosion of indigenous languages, cultural identity, and traditional knowledge. With nearly $80 \%$ of Natural WHSs intersecting at least one indigenous language, Disko et al. (2014: 3) underestimate considerably the indigenous presence at these reserves when they observe that indigenous territories are fully or partially located within nearly 100 of both types of WHSs, including more than one-third of Natural WHSs. However, because sites operate under a variety of governance and management arrangements, the extent of actual participation of indigenous groups in maintaining these sites varies tremendously. Indeed, in many sites indigenous peoples were not consulted before or during the nomination process and have no role in management. In 
such circumstances, World Heritage status can actually contribute to endangerment of indigenous peoples, their cultures and languages, by strengthening the claims of national governments and their refusal to acknowledge rights of indigenous stakeholders. Although free, prior and informed consent is already obligatory for inscription on the Lists of the Convention for the Safeguarding of the Intangible Cultural Heritage (UNESCO 2003) and the Convention's Register of Best Safeguarding Practices, this is not yet the case for the older WHC (Rössler 2016).

Over the past decade, various developments have set the stage for a new rights-based approach to engaging indigenous peoples and local communities in World Heritage stewardship and management of protected areas founded on free, prior informed consent (Stevens 2014). Adopting community in 2007 as the fifth "C" in its strategic objectives (with credibility, conservation, capacity-building, and communication), the WHC recognized the importance of involving indigenous, traditional, and local communities at all stages of the World Heritage process (UNESCO 2012b). In celebrating its 40th anniversary in 2012, the WHC adopted the theme "World Heritage and Sustainable Development: The Role of Local Communities", thereby expressing a commitment to deepen the involvement of indigenous peoples (Brown and Hay-Edie 2014). UNESCO's most recent operational guidelines mention indigenous peoples among various stakeholders with an interest and involvement in conservation and management of world heritage properties. UNESCO "encourages" state parties to ensure the "widest possible participation of stakeholders" in "identification, nomination and protection" and "to demonstrate, as appropriate, that the free, prior and informed consent of indigenous peoples has been obtained, through, inter alia making the nominations publicly available in appropriate languages and public consultations and hearings" (UNESCO 2016: 9;25). New standards evolving within the organization focus on linkages between cultural and natural heritage (Larsen 2012), and a new house-wide UNESCO policy on "Engaging with Indigenous Peoples" is under development for presentation to UNESCO's executive board in April 2017 (Rössler 2016).

With promotion and protection of cultural diversity a key policy focus of UNESCO, the WHC is currently the only mechanism for global governance and promotion of cultural diversity in the heritage sphere. But ensuring equal participation of indigenous communities in developing plans, laws, and policies relating to WHSs and bridging the gap between natural and cultural World Heritage management still requires more concerted effort (Lilley 2013; Logan 2014). Despite the establishment of so-called mixed sites in 1992 and cultural landscapes in 1993 to bridge the gap between nature and culture, the WHC's differentiation between cultural and natural heritage remains problematic for indigenous peoples whose approach to caring for their landbase is more holistic. Greater inclusion of indigenous peoples' knowledge and cultural values in planning and managing ecosystems will align the WHC more closely with the UN Convention on Biological Diversity (1992), requiring parties to "respect, preserve and maintain knowledge, innovations and practices of indigenous and local communities embodying traditional lifestyles relevant for the conservation and sustainable use of biological diversity and promote their wider application. (Article 8(j)." The World Heritage Centre has also been working with the International Union for Conservation of Nature (IUCN), one of three statutory Advisory Bodies to the WHC, on guidelines concerning best practice examples for the management and conservation of WHSs on lands or waters occupied or used by indigenous and traditional local communities (IUCN 2011; Larsen 2012; Larsen et al. 2014). Our findings can help to close the gaps in addressing indigenous rights and contribute to emerging policy standards and operational guidelines by preliminary identification of potential indigenous stakeholders for Natural WHSs. More careful analysis, such as 
participatory mapping, would provide essential guidance on individual sites, helping to conserve the natural and cultural diversity so important to our planet.

Open Access This article is distributed under the terms of the Creative Commons Attribution 4.0 International License (http://creativecommons.org/licenses/by/4.0/), which permits unrestricted use, distribution, and reproduction in any medium, provided you give appropriate credit to the original author(s) and the source, provide a link to the Creative Commons license, and indicate if changes were made.

\section{References}

Australian Institute of Aboriginal and Torres Strait Islander Studies and Federation of Aboriginal and Torres Strait Islander Languages (2005) National indigenous languages survey report 2005. Commonwealth of Australia, Canberra

Biddle N (2012) Indigenous language usage. Canberra, Centre for aboriginal economic policy research school of social sciences, Australian National University, Canberra

Bijoy CR (2014) Western Ghats of India: a natural heritage enclosure? In: Disko S, Tugendhat H (eds) World heritage sites and indigenous peoples' rights. International Work Group for Indigenous Affairs, Copenhagen, pp 23-243

Bright EA, Coleman PR, Rose AN, Urban ML (2011) LandScan 2010 high-resolution global population dataset. Oak Ridge National Laboratory, Oak Ridge

Brown J, Hay-Edie T (2014) Engaging local communities in stewardship of world heritage. World Heritage Paper Series No. 40. UNESCO, Paris

Convention on Biological Diversity (1992) United Nations Environment Programme http://www.cbd.int/ convention/. Accessed 31 July 2016

Dalberg Global Development Advisors (2016) Protecting people through nature. Natural world heritage sites as drivers of sustainable development. World Wide Fund for Nature, Gland, Switzerland

Disko S, Tugendhat H, García-Alix L (2014) World heritage sites and indigenous peoples' rights. An introduction. In: Disko S, Tugendhat $\mathrm{H}$ (eds) World heritage sites and indigenous peoples' rights. International Work Group for Indigenous Affairs, Copenhagen, pp 3-37

Dudley N (ed) (2008) Guidelines to applying protected area management categories. IUCN, Gland

Ens EJ, Pert P, Clarke PA, Budden M, Club L, Doran B, Douras C, Gaikwad J et al (2015) Indigenous biocultural knowledge in ecosystem science and management: review and insight from Australia. Biol Conserv 181:133-149

Figgis P, Leverington A, Mackay R, Maclean A, Valentine P (eds) (2012) Keeping the outstanding exceptional: the future of world heritage in Australia. Australian Committee for IUCN, Sydney

Foley JA, DeFries R, Asner GP, Barford C, Bonan G, Carpenter SR, Chapin FS, Coe MT et al (2005) Global consequences of land use. Science 309:570-574

Global Mapping International (2015a) World language mapping system. Global Mapping International, Colorado Springs, Colorado. URL: http://www.gmi.org/wlms. Accessed 15 March 2015

Global Mapping International (2015b) Global Mapping International, World language mapping system, Version 17. Global Mapping International, Colorado Springs, CO

Gorenflo LJ, Romaine S, Mittermeier RA, Walker K (2012) Co-occurrence of linguistic and biological diversity in biodiversity hotspots and high biodiversity wilderness areas. Proc Natl Acad Sci 109:80328037

Gorenflo LJ, Romaine S, Musinsky S, Denil M, Mittermeier RA (2014) Linguistic diversity in high biodiversity regions. Conservation International, Arlington

Hill R, Cullen-Unsworth LC, Talbot LD, McIntyre-Tamwoy S (2011) Empowering indigenous peoples' biocultural diversity through world heritage cultural landscapes: a case study from the Australian tropical forests. Int J Herit Stud 17:571-591

International Union for the Conservation of Nature (IUCN) (2011) Indigenous communities and conserved areas: A bold new frontier for conservation. http://www.iucn.org/content/indigenous-and-communityconserved-areas-bold-new-frontier-conservation. Accessed 4 May 2015

IUCN and United Nations Development Programme-World Conservation Monitoring Centre (UNEPWCMC) (2016) The world database on protected areas (WDPA), July 2016. UNEP-WCMC, Cambridge

Larsen PB (2012) IUCN, world heritage and evaluation processes related to communities and rights. An independent review. IUCN, Gland 
Larsen PB, Oviedo GT, Badman T (2014) World heritage, indigenous peoples and rights: an IUCN perspective. In: Disko S, Tugendhat $\mathrm{H}$ (eds) World heritage sites and indigenous peoples' rights. International Work Group for Indigenous Affairs, Copenhagen, pp 65-101

Leverington F, Costa KL, Courrau J, Pavese H, Nolte C, Marr M, Coad L, Burgess LN, Bomhard B, Hockings M (2010) Management effectiveness in protected areas-A global assessment, 2nd edn. University of Queensland, Brisbane

Lewis MP, Simons GF (2010) Assessing endangerment: expanding Fishman's GIDS. Romanian Rev Linguist 55:103-120

Lewis MP, Simons GF, Fennig CD (2013) Ethnologue: languages of the world, 17th edn. SIL International, Dallas

Lilley I (2013) Nature and culture in world heritage management: a view from the Asia-Pacific (or, never waste a good crisis!). Terra Australis 36:13-22

Logan W (2014) Heritage rights-Avoidance and reinforcement. Herit Soc 79:156-169

Loh J, Harmon D (2014) Biocultural diversity: Threatened species, endangered languages. World Wide Fund for Nature, Zeist

Maffi L (2005) Linguistic, cultural, and biological diversity. Annu Rev Anthropol 29:599-617

Marmion D, Obata K, Troy J (2014) Community, identity, wellbeing: the report of the second national indigenous languages survey. Australian Institute of Aboriginal and Torres Strait Islander Studies, Canberra

McDonald JA, Cawardine J, Joseph LN, Klein CJ, Rout TM, Watson JEM, Garnett ST, McCarthy MA, Possingham H (2015) Improving policy efficiency and effectiveness to save more species: a case study of the megadiverse country Australia. Biol Cons 182:102-108

Nettle D, Romaine S (2000) Vanishing voices. The extinction of the world's languages. Oxford University Press, New York

Palmer M (2016) Sustaining indigenous geographies through world heritage: a study of Uluru-Kata Tjuta National Park. Sustain Sci 11:13-24

Pretty J, Adams B, Berkes F, de Athayde SF, Dudley N, Hunn E, Maffi L, Milton K et al (2009) The intersections of biological diversity and cultural diversity: towards integration. Conserv Soc 7:100-112

Rössler M (2016) Foreword: the changing landscape of indigenous heritage protection. In: Grant P (ed) State of the world's minorities and indigenous peoples. Minority Rights Group International, London, pp 1015

SIL (n.d.) SIL International website. http://www.sil.org. Accessed 26 March 2015

Stevens S (ed) (2014) Indigenous peoples, national parks, and protected areas. A new paradigm linking conservation, culture, and rights. University of Arizona Press, Tucson

UNESCO (2003) Convention for the safeguarding of intangible cultural heritage. UNESCO, Paris

UNESCO (2005) Basic texts of the 1972 world heritage convention. UNESCO, Paris

UNESCO (2012a) Managing natural world heritage. UNESCO, Paris

UNESCO (2012b) World heritage and indigenous peoples. World Heritage Review 62

UNESCO (2016) Operational guidelines for the implementation of the World Heritage Convention. UNESCO, Paris. http://whc.unesco.org/en/guidelines. Accessed 8 March 2017

UNESCO (n.d.) UNESCO World Heritage Convention. http://whc.unesco.org/en/convention/. Accessed 26 March 2016

United Nations (2007) Declaration on the rights of indigenous peoples. United Nations, New York

United Nations Environment Programme-World Conservation Monitoring Centre (2015) World database on protected areas user manual 1.0. UNEP-WCMC, Cambridge, UK 